\title{
Late Presentation of Congenital Diaphragmatic Hernia with Malrotation of Midgut in Adult
}

Vimala G, Bagadeesh Palanisamy ${ }^{*}$, Kannan Ross

Institute of general surgery, Madras medical college\& Rajiv Gandhi Government General Hospital, Chennai, Tamilnadu, India

DOI: $10.36347 /$ sasjs.2020.v06i02.003

| Received: 01.02.2020 | Accepted: 07.02.2020 | Published: 12.02.2020

*Corresponding author: Dr. Bagadeesh Palanisamy

\section{Abstract}

18 years old female admitted with complaints of abdominal pain, breathlessness and constipation for 2 days. On examination patient had tachycardia, tachypnea, abdomen symmetrically distended with tenderness on left side. Heart sounds S1 and S2 was heard on right side of the chest, decreased air entry on left side. X ray and CT chest showed diaphragmatic hernia with bowel obstruction. Patient was taken for emergency procedure content reduced and defect was closed, respiratory support given. Clinical and radiological investigations helps in diagnosing the congenital diaphragmatic hernia early and intervention before respiratory failure increases the survival rate in both neonates and adults.

Keywords: Malrotation of midgut, respiratory distress, adult, $\mathrm{x}$ ray.

Copyright @ 2020: This is an open-access article distributed under the terms of the Creative Commons Attribution license which permits unrestricted use, distribution, and reproduction in any medium for non-commercial use (NonCommercial, or CC-BY-NC) provided the original author and source are credited.

\section{INTRODUCTION}

The aim of this case report is to provide information on the clinical symptoms and signs, diagnosis and management of the late presentation of congenital diaphragmatic hernia in adult.Congenital diaphragmatic hernia is a major malformation occasionally found in newborns and babies. Congenital diaphragmatic hernia is defined by the presence of an orifice in the diaphragm, more often to the left and posterolateral, which permits the herniation of abdominal contents into the thorax. In our case the patient presented with small bowel obstruction due to diaphragmatic hernia Bochdalek type with malrotation of midgut.

\section{CASE REPORT}

The subject is an 18 years old female admitted with complaints of abdominal pain and breathlessness for 2 days with history of constipation and has not passed flatus for 2 days. Patient was first born child and neonatal period was uneventful with no previous significant medical and surgical history. On general examination patient is conscious, afebrile. Tachycardia and tachypnea present, abdomen symmetrically distended with tenderness in left hypochondrium, lumbar and iliac fossa region. On Cardiovascular system examination $\mathrm{S} 1$ and $\mathrm{S} 2$ heard on right side of the chest, Respiratory system examination revealed decreased air entry and bowel sounds heard on left side.
$\mathrm{X}$ ray chest and abdomen showed bowel shadows in left chest, on CT chest showed mediastinal shift to right side, collapse of left lung, bowel loop in left chest. CT abdomen revealed Ileum, transverse colon proximal descending colon herniating into the thorax. Jejunum, Transverse $\&$ ascending colon appeared dilated, Distal descending colon is collapsed and recto sigmoid on right side.

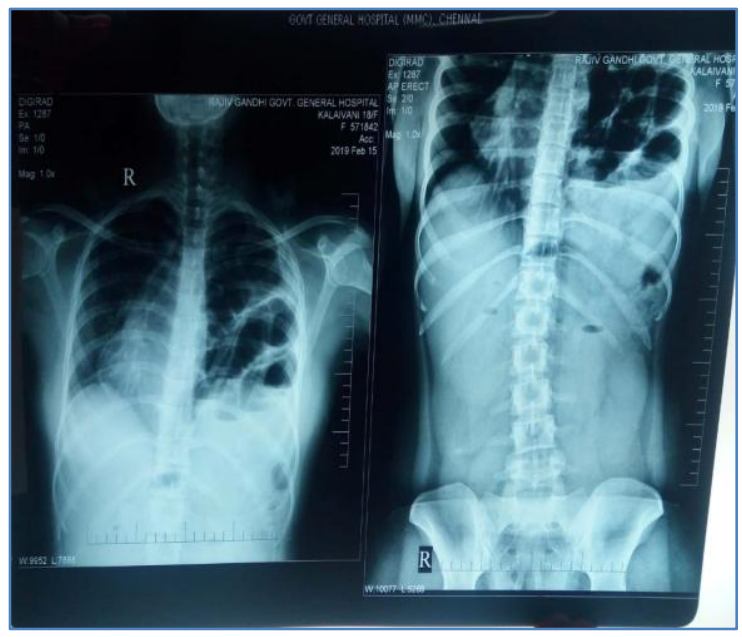

Fig-1: Plain X ray of chest and abdomen showing bowel loops in left hemithorax 


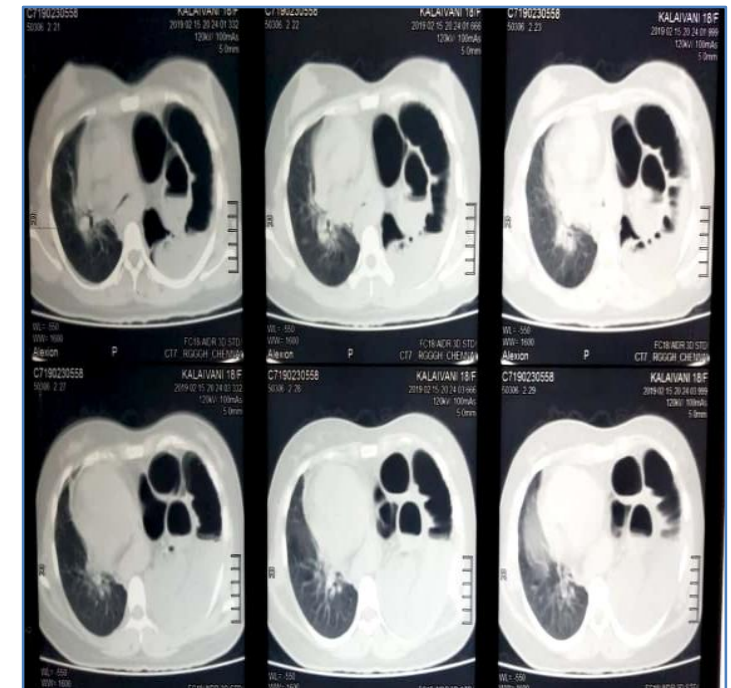

Fig-2: CT scan chest showing gross mediastinal shift to right side, complete collapse of left lung and left hemithorax occupied by bowel loops

Due to small bowel obstruction and respiratory distresspatient was taken for emergency procedure through left subcostal incision peritoneal cavity entered - jejunum was dilated, ileum, cecum with appendix, transverse colon was found herniating into the thorax, content was reduced and defect of size $6.5^{*} 4 \mathrm{~cm}$ noted in posterolateral surface of diaphragm which was closed by using non absorbable suture material prolene in two layers.

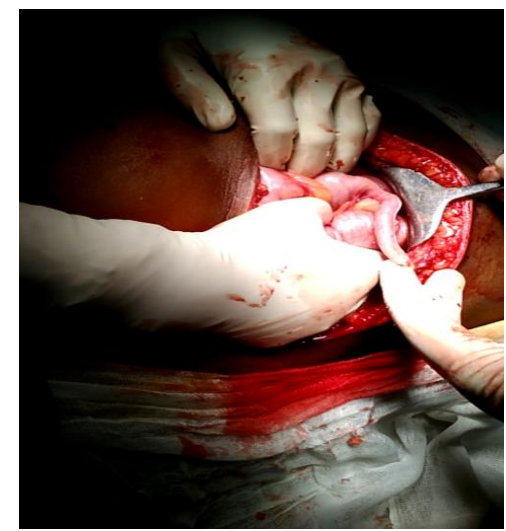

Fig-3: Intra operative picture showing ceacum with appendix on left side of the chest

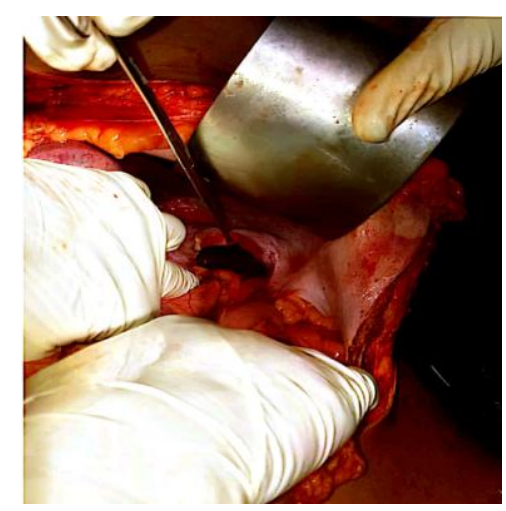

Fig-4: Defect in posterolateral surface of diaphragm

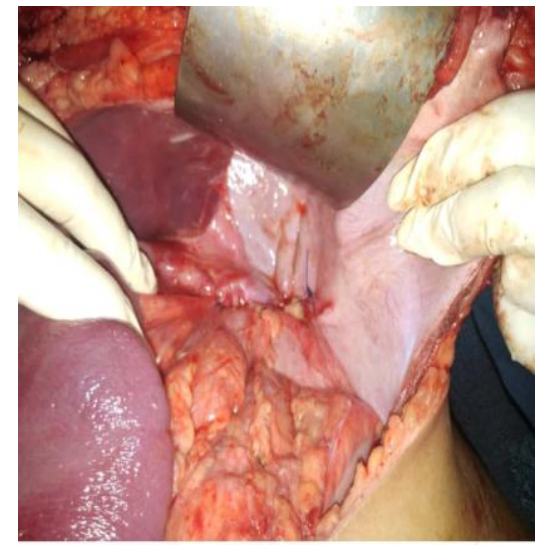

Fig-5: Defect was closed by non absorbable suture material

Intercostal drainage tube was inserted on the left side. Patient was on mechanical ventilation for 4 days after that she was weaned gradually and oral feeds started.

\section{DISCUSSION}

Incidence is 1 in 2000 to 5000 live births and common in left side around $80 \%$ and bilateral in $<5 \%$ of the cases. Hernia sac is present in $20 \%$ and overall survival rate 70 to $90 \%$. Incidence in adult is 0.1 to $6 \%$ and most cases are sporadic.

\section{Associated anomalies}

CNS lesions, Omphalocele, Esophageal atresia, cardiovascular lesions, Part of trisomy 21, 13, 18.

\section{Pathophysiology}

$\mathrm{CDH}$ is due to failure of closure of pleuroperitoneal canal in developing fetus. Usually the pleuroperitonealcavity become separated by the developing membrane during 8 to 10 weeks of gestation. When this process fails the pleuoperitoneal canal does not close and a posterolateral defect in diaphragm results.It impairs growth of ipsilateral lung and causes pulmonary hypertension

\section{Clinical features}

Respiratory distress at birth (tachypnea, grunting, use of accessory muscles - cardinal sign), Dyspnea, Cyanosis, Scaphoidabdomen, Increased chest wall diameter, Bowel sound heard in chest, Decreased/absent breath sound on side of hernia, Shifting of apex beat to the opposite side

\section{Surgical treatment}

Mostly surgery was done $48 \mathrm{hrs}$ of birth after stabilization. Preferred approach is sub costal abdominal incision both laparoscopic and thoracoscopic repair can be done. Content reduced and defect closed by interrupted non absorbable sutures, if present the hernia sac should be excised. If primary closure is not possible -abdominal /thoracic muscle flaps can be used. For tension free repair native tissue / Prosthetic material 
Synthetic patch (GORE TEX) and biological mesh are used.

\section{Prognosis}

Overall survival $67 \%$ in newborns and poor prognosis in major anomalies, severe pulmonary hypoplasia - need of ECMO. In adults prognosis is good if surgery is done before developing respiratory complications.

\section{CONCLUSION}

Congenital diaphragmatic hernias are usually diagnosed in neonatal period it may present as late in adults with incidence of 0.17 to $6 \%$. Clinical and radiological investigations help in diagnosing the condition, early intervention before respiratory failure increases the survival rate in both neonates and adults. In our case early diagnosis and early intervention saved the patient before developing complications.

\section{REFERENCES}

1. Gattot D, Boda C, Ughetto S, Perthus I, RobertGnansia E, Francannet C, Laurichesse-Delmas H, Jani J, Coste K, Deprest J, Labbe A, Sapin V, Lemery D: Prenatal detection and outcome of congenital diaphragmatic hernia: a French registry- based study. Ultrasound ObstetGynecol. 2007, 29:276-283.

2. Torfs CP, Curry CJ, Bateson TF, Honore LH: A population-based study of congenital diaphragmatic hernia. Teratology. 1992, 46:555565.

3. Yang W, Carmichael SL, Harris JA, Shaw GM: Epidermiologic characteristics of congenital diaphragmatic hernia among 2.5 million California births. 1989-1997.

4. Birth Defects Res A Clin Mol Teratol. 2006, 76:170-174.

5. Sinha CK, Islam $\mathrm{S}$, Patel $\mathrm{S}$, Nicolaides $\mathrm{K}$, Greenough A, Devenport M: Congenital diaphragmatic hernia: prognostic indices in the fetal endoluminal tracheal occlusion era. J Pediatr Surg. 2009, 44:312-316.

6. Bronshtein M, Lewit N, Sujov PO, Markoul IR, Blazer S: Prenatal diagnosis of congenital diaphragmatic hernia: timing of visceral herniation and outcome. Pren Diagn. 1995, 15:695-698.

7. Jesudason EC. Challenging embryological theories on congenital diaphragmatic hernia: future therapeutic implications for paediatricsurgery. Ann R CollSurg Engl. 2002, 84:252-259. 